\title{
Effect of Process Parameters on Extraction of Pectin from Sweet Lime Peels
}

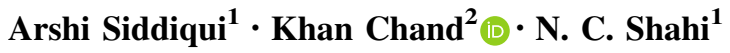

Received: 30 October 2020/Accepted: 25 January 2021/Published online: 5 April 2021

(C) The Author(s) 2021

\begin{abstract}
Pectin is a heterogeneous polysaccharide found in the cell wall, middle lamellae of many fruits and vegetables, and is widely used as gelling agent, emulsifier and stabilizer in food industry. In keeping the importance of pectin in the food industry, ultrasound-assisted extraction of pectin from sweet lime peel was investigated. The individual and interactive effect of solid-solvent ratio, ultrasound power intensity and sonication time on the pectin yield, equivalent weight and methoxyl content were studied and analyzed using multiple regression analysis. The maximum pectin yield $(36.4 \mathrm{~g} / 100 \mathrm{~g})$, equivalent weight $(740.3 \mathrm{mg})$ and methoxyl content $(7.1 \%)$ was obtained under optimal condition (solid-solvent ratio of $1: 24.3 \mathrm{~g} / \mathrm{ml}$, ultrasound power intensity of $80 \mathrm{~W} / \mathrm{cm}^{2}$ and sonication time of $18.4 \mathrm{~min})$. Significant $(p<0.05)$ effect of process parameters was found in all responses of pectin extracted from sweet lime peel. It was also revealed from the present study that ultrasound-assisted extraction of pectin from sweet lime peel is an efficient approach toward waste valorization and extraction of pectin with high yield and good quality attributes.
\end{abstract}

Keywords Sweet lime peel · Pectin .

Ultrasound-assisted extraction and pectin yield

Khan Chand

kcphpfe@gmail.com

1 Department of Post Harvest Process and Food Engineering, College of Technology, G.B. Pant University of Agriculture and Technology, Pantnagar, Uttarakhand 253145, India

2 Department of Agricultural Engineering, School of Agricultural Sciences and Rural Development, Central University of Nagaland, Medziphema, Dimapur, Nagaland 797106, India

\section{Introduction}

Waste utilization is one of the major concerns in the food processing industry and it has a great potential to provide economic, social and environmental benefits to a country [5]. The waste from households accounts for $42 \%$ while food manufacturing industry adds 39\%, 14\% losses occur in food service sector and 5\% food waste during distribution chain [14]. The inadequate waste management can cause several health hazards as well as environmental issues. Hence, necessary steps should be taken to reduce waste levels and finding the most sustainable solution to manage the remaining waste. Food waste can be converted into high-value products such as antioxidants, bioactive, bioethanol, industrial enzyme, films, nutraceuticals, pigments, protein, sugar, etc. which would provide certain economic benefit for the agri-food sector and a positive environmental impact [23]. Citrus fruit is one of the most extensively consumed and processed fruit in the world which constitute about $18 \%$ of total world fruit production [10]. Citrus fruits are highly consumed as fresh produce and juice worldwide, and most commonly its peel is discarded as waste [19]. Due to both economic and environmental factors, the disposal of citrus peel waste has considerable constraints. Thus, the conversion of citrus peel waste into valuable products provides both economic and environmental benefits. Citrus peels can be used as a great source for the retrieval of pectin, bioactive compounds, organic acids, enzymes and essential oils [13]. Citrus limetta is a species of citrus, commonly known as mosambi, sweet lime, sweet lemon and sweet limetta. It belongs to the family of "Rutaceau" and is the third largest fruits produced in India. Sweet lime contains active phytochemicals that can protect health. It is also a rich source of various nutrients like vitamin $\mathrm{C}$ and minerals that make 
it one of the important commercial citrus fruit crops used by juice processing industries [20]. In India, sweet lime juice is a favorite citrus drink, while its peel discarded as waste can be utilized for extraction of various value-added products. Sweet lime peel is considered as a rich and important pectin source. Pectin is the most widely used polysaccharide in food industry, which can be extracted from peels of fruits. It is also used in pharmaceutical industries as antitumor, antioxidant, antidiabetic and anticancer drug [8]. Pectin is used as a good additive in jams, soft drinks and milk products [26]. Pectin is also used as fat substitute in emulsified meat products, spreads, ice cream and salad dressing [7]. Pectin is considered as an effective biomaterial film due to its biodegradability, biocompatibility and non-toxicity [22]. Extraction is one of the essential techniques which is used to recover pectin from various organic and inorganic wastes. Extraction technique can be carried out by both conventional and non-conventional methods. However, the conventional extraction methods have numerous limitations like long processing time, high energy requirement and high solvent consumption with high amount of waste water generation. Thus various novel approaches like microwave-assisted extraction, ultrasound-assisted extraction and enzyme-assisted extraction were developed for the extraction process [20]. Among various extraction techniques, ultrasound-assisted extraction technique is considered more beneficial due to low energy consumption, shortened treatment time, less solvent usage, increased safety of the operators, and increased yield [2]. It is a non-thermal extraction technique in which sound waves, having frequencies higher than $20 \mathrm{kHz}$ travel in matter and induce expansion and compression cycles, leading to the formation of cavitation bubbles. The collapse of cavitation bubbles near cell walls induced by ultrasound produces cell disruption, thus causing stronger and enhanced solvent entrance into the cells and intensification of the mass transfer [24]. Ultrasound-assisted extraction is widely used in food industry due to its capability to induce chemical and physical changes of food components. Also, ultrasound processing has some of the improvements on foods such as increased emulsifying capacity, release and diffusion of cell material and enhanced foaming [6]. Several authors already reported the extraction of pectin from various citrus fruits. However, none research report has been found on the ultrasound-assisted extraction of pectin from waste sweet lime peel.

\section{Materials and Methods}

\section{Materials and Reagents}

Sweet lime peel (10 kg, IMC $80 \%)$ was procured from the local market of Pantnagar, Uttarakhand. It was cleaned, washed and dried using tray drier at $60{ }^{\circ} \mathrm{C}$ for $48 \mathrm{~h}$. The dried peel (2-3 kg) was ground using hammer mill (Make: Butex Engineering Company, Kanpur) and sieved into fine powder of size 300 microns. The obtained powder (1-2 kg) was stored in sealed plastic bags prior to experiments. Citric acid was mixed in deionized water to prepare acidic medium of $\mathrm{pH} 1.8$ for pectin extraction.

\section{Ultrasound-assisted Extraction of Pectin}

Ten (10) grams dried sweet lime peel powder was weighed and mixed with the solvent (Citric acid) in the solid-solvent ratio $(1: 18,1: 24$ and 1:30 $\mathrm{g} / \mathrm{ml})$ in the beaker. The mixture solution was then placed under probe $(20 \mathrm{~mm}$ diameter) of ultrasonication apparatus (Electronic industries modelEI-250, 230 VAC Single phase, 250 watts ultrasonic power) at ultrasound power intensity (48, 64 and $80 \mathrm{~W} /$ $\left.\mathrm{cm}^{2}\right)$ and time $(15,25$ and $35 \mathrm{~min})$ combinations for extraction of pectin given in Table 1. After completion of the set time of extraction, the suspension was filtered using muslin cloth and centrifuged (8000 rpm for $15 \mathrm{~min}$ ). The supernatant was precipitated with equal volume of ethanol and was left untouched for an hour. The coagulated pectin was washed 2-3 times with ethanol to remove mono and disaccharides. Extracted wet pectin was then dried in hot air oven at $45{ }^{\circ} \mathrm{C}$ until it attains a constant weight. After drying, the dry pectin mass was milled to powdered pectin form and stored for analysis.

\section{Quantitative and Qualitative Analysis of Pectin}

\section{Yield Estimation}

The extraction yield is the amount of extract recovered in mass compared with the initial amount of whole plant. It is a measure of efficiency of the solvent to extract specific components from the original material. The dry extract obtained after filtration was weighed to get the extraction yield [21]. The yield of the extract calculated using formula:

Pectin Yield $(\mathrm{g} / 100 \mathrm{~g})=\frac{\text { Weight of Pectin }}{\text { Weight of drypowder }} \times 100$

Equivalent Weight

Equivalent weight is an important physical property of pectin. It is the most important characteristic in 
Table 1 Box-Behnken design with the observed values for pectin yield, equivalent weight and methoxyl content of ultrasound-assisted extraction of pectin from sweet lime peel

\begin{tabular}{|c|c|c|c|c|c|c|}
\hline \multicolumn{2}{|c|}{ Factors } & \multicolumn{2}{|l|}{ Unit } & \multicolumn{3}{|l|}{ Levels } \\
\hline & & & & -1 & 0 & 1 \\
\hline \multicolumn{2}{|c|}{ Solid-solvent ratio $\left(X_{1}\right)$} & \multicolumn{2}{|l|}{$\mathrm{g} / \mathrm{ml}$} & $1: 18$ & $1: 24$ & $1: 30$ \\
\hline \multicolumn{2}{|c|}{$\begin{array}{l}\text { Ultrasound power intensity } \\
\left(X_{2}\right)\end{array}$} & & $\mathrm{W} / \mathrm{cm}^{2}$ & 48 & 64 & 80 \\
\hline \multicolumn{2}{|c|}{ Sonication time $\left(X_{3}\right)$} & \multicolumn{2}{|l|}{ Min } & \multirow{2}{*}{$\begin{array}{l}15 \\
\text { Pectin Yield }(\mathrm{g} / \\
100 \mathrm{~g})\end{array}$} & \multirow{2}{*}{$\begin{array}{l}25 \\
\text { Equivalent Weight } \\
(\mathrm{mg})\end{array}$} & \multirow{2}{*}{$\begin{array}{l}35 \\
\text { Methoxyl Content } \\
(\%)\end{array}$} \\
\hline $\begin{array}{l}\text { Exp. } \\
\text { no }\end{array}$ & $\begin{array}{l}\text { Solid-solvent } \\
\text { ratio } \\
\left(X_{1}, \mathrm{~g} / \mathrm{ml}\right)\end{array}$ & $\begin{array}{l}\text { Ultrasound power } \\
\text { intensity } \\
\left(X_{2}, \mathrm{~W} / \mathrm{cm}^{2}\right)\end{array}$ & $\begin{array}{l}\text { Sonication } \\
\text { time } \\
\left(X_{3}, \min \right)\end{array}$ & & & \\
\hline 1 & $1: 24$ & 48 & 35 & 34.3 & 722.7 & 6.9 \\
\hline 2 & $1: 30$ & 64 & 35 & 36.8 & 750.4 & 6.9 \\
\hline 3 & $1: 24$ & 64 & 25 & 30.8 & 671.1 & 7 \\
\hline 4 & $1: 24$ & 80 & 35 & 36.9 & 795.2 & 7.1 \\
\hline 5 & $1: 24$ & 64 & 25 & 32.5 & 691.1 & 7 \\
\hline 6 & $1: 24$ & 48 & 15 & 31.5 & 677 & 6.9 \\
\hline 7 & $1: 24$ & 64 & 25 & 31.1 & 671.4 & 7 \\
\hline 8 & $1: 24$ & 80 & 15 & 38.8 & 770.3 & 7.1 \\
\hline 9 & $1: 24$ & 64 & 25 & 31.3 & 671.6 & 7 \\
\hline 10 & $1: 18$ & 80 & 25 & 26.2 & 582.3 & 7 \\
\hline 11 & $1: 30$ & 64 & 15 & 27.9 & 583.6 & 6.8 \\
\hline 12 & $1: 24$ & 64 & 25 & 30.6 & 671.2 & 7 \\
\hline 13 & $1: 18$ & 64 & 35 & 28.1 & 599.5 & 6.8 \\
\hline 14 & $1: 30$ & 80 & 25 & 36.5 & 731.7 & 7 \\
\hline 15 & $1: 18$ & 64 & 15 & 31.2 & 671.4 & 6.8 \\
\hline 16 & $1: 18$ & 48 & 25 & 29.2 & 609.5 & 6.7 \\
\hline 17 & $1: 30$ & 48 & 25 & 25.2 & 566.2 & 6.9 \\
\hline
\end{tabular}

determining the functional behavior of pectin. $0.5 \mathrm{~g}$ sample was taken in a $250 \mathrm{ml}$ conical flask, and $5 \mathrm{ml}$ ethanol was added. $1 \mathrm{~g}$ of sodium chloride to sharpen the end point and $100 \mathrm{ml}$ of distilled water were added. Finally, 6 drops of phenol red were added and titrated against $0.1 \mathrm{~N} \mathrm{NaOH}$. Titration point was indicated by pink color [21]. Equivalent weight was calculated by the given formula:

Equivalent weight $(\mathrm{mg})=\frac{\text { Weight of sample } \times 1000}{\text { Volume of alkali } \times \text { Normality of alkali }}$

\section{Methoxyl Content}

Methoxyl content was determined by saponification of the pectin and titration of the liberated carboxyl groups. The neutralized solution obtained during the determination of equivalent weight was collected, and $25 \mathrm{ml}$ of $0.25 \mathrm{~N}$ $\mathrm{NaOH}$ was added. The mixture was stirred thoroughly and kept at ambient temperature for $30 \mathrm{~min}$. Then, $25 \mathrm{ml}$ of $0.25 \mathrm{~N} \mathrm{HCl}$ was added and titrated against $0.1 \mathrm{~N} \mathrm{NaOH}$ to the end point [21]. Methoxyl content was calculated using the equation:

Methoxyl content $(\%)=\frac{\text { Volume of alkali } \times \text { Normality of alkali } \times 3.1}{\text { Weight of sample }}$

\section{Statistical Design}

Three factors, three levels $(-1,0,1)$ Box-Behnken design of response surface methodology was employed to investigate and optimize the effect of process variables on the yield and quality of pectin extracted from sweet lime peel, shown in Table 1. A total 17 experiments with 5 center points were designed using Design Expert software 10.0.1. The data collected were subjected to regression analysis to determine the existing relationship between independent and dependent variables. Each response was represented by a mathematical equation that correlates the response surfaces. The response was then expressed as second-order polynomial equation 
$\begin{aligned} \mathrm{Y} & =\beta_{0}+\sum_{i=1}^{n} \beta_{i} X_{i}+\sum_{i=1}^{n} \beta_{i i} X_{i}^{n} \\ & +\sum_{i=1}^{n} \sum_{j=i=1}^{n} \beta_{i i} X_{i} X_{j}\end{aligned}$

where,

$Y=$ response, $\beta_{0}, \beta_{i}, \beta_{i i}$ are regression coefficients and $n=$ number of independent variables $(n=3) . X_{i}$ and $X_{j-}$ $=$ independent variables (where, $i=1,2, \ldots n$ and $j=1,2$ ...n).

\section{Results and Discussion}

\section{Analysis of Pectin Yield, Equivalent Weight and Methoxyl Content}

As results given in Table 1, Box-Behnken design was employed to optimize the variables of ultrasound-assisted extraction process (UAE) and examine their effects on the responses (pectin yield, equivalent weight, methoxyl content). The results indicated that the pectin yield was in the range $25.2-38.8 \mathrm{~g} / 100 \mathrm{~g}$, as experiment no. 17 and 8 had the lowest and highest yield, respectively. The maximum pectin yield was found under the experimental conditions of solid-solvent ratio of $1: 24 \mathrm{~g} / \mathrm{ml}$, ultrasound power intensity at $80 \mathrm{~W} / \mathrm{cm}^{2}$ and sonication time $15 \mathrm{~min}$. The maximum pectin yield might be due to the maximum level of ultrasound power intensity and the low $\mathrm{pH}$ extracting solvent used in the extraction process. At sufficiently higher ultrasound power intensity, UAE increases rupture of sweet lime cell wall matrix, leading to better interactions between solvent and extracted material and thus increased the pectin yield. Also, the lower acidic extraction solvent has the ability to contact directly with the insoluble pectin and favored the hydrolysis of the insoluble pectin constituents into soluble pectin, thus increasing the pectin yield [12]. However, the minimum pectin yield was obtained under the experimental conditions of solid-solvent ratio of $1: 30 \mathrm{~g} / \mathrm{ml}$, ultrasound power intensity at $48 \mathrm{~W} / \mathrm{cm}^{2}$ and sonication time at $25 \mathrm{~min}$. This might be due to the higher solid-solvent ratio and lower ultrasound power intensity levels. The higher solid-solvent ratio affects the extraction yield negatively and also it complicates the recovery of pectin during the further extraction step by alcohol precipitation. Thus, further increment in solid-solvent ratio leads to decrement in pectin yield. Similar effect was observed for ultrasound-assisted extraction of pectin from pomegranate peel [16]. The equivalent weight of extracted pectin was found to be ranged from 566.2 to $795.2 \mathrm{mg}$. The maximum and minimum value of equivalent weight was found in experiment no. 4 and 17, respectively. The higher equivalent weight obtained at experimental conditions of solid-solvent ratio of $1: 24 \mathrm{~g} / \mathrm{ml}$, ultrasound power intensity at $80 \mathrm{~W} / \mathrm{cm}^{2}$ and sonication time at $35 \mathrm{~min}$ might be due to higher ultrasound power intensity which facilitates the release of higher amount of pectin. However, the lower equivalent weight was obtained under experimental conditions of solid-solvent ratio of $1: 30 \mathrm{~g} / \mathrm{ml}$, ultrasound power intensity at $48 \mathrm{~W} / \mathrm{cm}^{2}$ and sonication time at $25 \mathrm{~min}$. This reduction could be due to higher partial degradation of pectin during extraction. Similarly, the methoxyl content of extracted pectin varied from 6.7 to $7.1 \%$, as experiment no. 4 and 16 had the maximum and minimum value of methoxyl content, respectively. The maximum methoxyl content was obtained under experimental conditions of solid-solvent ratio of $1: 24 \mathrm{~g} / \mathrm{ml}$, ultrasound power intensity at $80 \mathrm{~W} / \mathrm{cm}^{2}$ and sonication time at $35 \mathrm{~min}$. The higher value of methoxyl content might be because of the presence of more free esterified carboxyl group in the pectin. On the other hand, the minimum methoxyl content was obtained at experimental conditions of solid-solvent ratio of $1: 18 \mathrm{~g} / \mathrm{ml}$, ultrasound power intensity at $48 \mathrm{~W} / \mathrm{cm}^{2}$ and sonication time at $25 \mathrm{~min}$. The lesser solid-solvent ratio and ultrasound power intensity leads pectin having less free esterified carboxyl group present in the pectin chain and thus lower the methoxyl content. Therefore, optimal process conditions were investigated in order to obtain the maximum extraction yield, equivalent weight and methoxyl content of pectin extracted from sweet lime peel using ultrasound-assisted extraction technique. The maximum production of pectin was obtained at solid-solvent ratio of $1: 24.3 \mathrm{~g} / \mathrm{ml}$, ultrasound power intensity of $80 \mathrm{~W} / \mathrm{cm}^{2}$ and sonication time of 18.4 min as shown in Fig. 1 and 2.

\section{Statistical Analysis of Pectin Yield, Equivalent Weight and Methoxyl Content}

The statistical significance of the proposed quadratic model for pectin yield, equivalent weight and methoxyl content

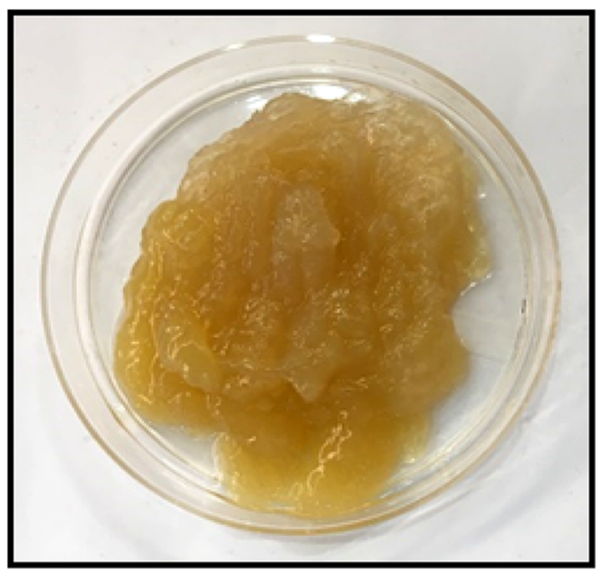

Fig. 1 Extracted wet pectin in jelly form 


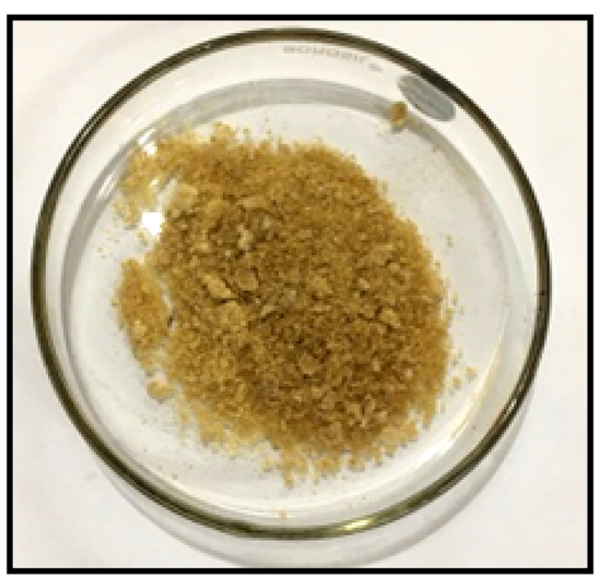

Fig. 2 Dried pectin in powder form

was evaluated by ANOVA, and the results were listed in Table 2. In this analysis, the $\mathrm{F}$ value of model for the pectin yield, equivalent weight and methoxyl content was 32.75 , 79.70 and 1173.89 , which was associated with $p$ value of $<0.0001$ in all the responses. The high $\mathrm{F}$ value and low $\mathrm{p}$ value indicated that all the proposed models are extremely significant and the responses were significantly affected by the extraction factors. Also, lack of fit value for regression models was not found significant, which indicated that the model equation was adequate to describe the pectin yield, equivalent weight and methoxyl content. In addition, $\mathrm{R}^{2}$ value for pectin yield, equivalent weight and methoxyl content was $0.9768,0.9903$ and 0.9993 , respectively, which implies that the model could account for $97.68 \%, 99.03 \%$ and $99.93 \%$ data, respectively. For better suitability of the model, the difference between the predicted and adjusted coefficient of determination should be less than 0.2 , the adequate precision should be greater than 4 and whereas coefficient of variation should not exceed $10 \%$. In this case, "Pred $R^{2}$ " of $0.7603,0.9067$ and 0.9911 was in reasonable agreement with the "Adj $R^{2}$ " of 0.9470 , 0.9779 and 0.9985 , respectively for pectin yield, equivalent weight and methoxyl content. The adequate precision values of $19.038,30.683$ and 111.632 and the coefficient of variation of $2.83 \%, 1.50 \%$ and $0.066 \%$ were calculated for pectin yield, equivalent weight and methoxyl content, respectively, thereby verifying the accuracy suitability of model. The coefficient of determination $\left(R^{2}\right)$ and adjusted determination coefficient ( $\operatorname{Adj} R^{2}$ ) were reasonably close to 1 , indicating a high degree of correlation between the observed and predicted values.

Based on these results, the surface models for yield, equivalent weight and methoxyl content of pectin extracted from sweet lime peel using ultrasound-assisted extraction technique were formulated as given below

$$
\begin{aligned}
\text { Pectin Yield }\left(\frac{\mathrm{g}}{100 \mathrm{~g}}\right)= & 31.26+1.46 X_{1}+2.28 X_{2}+0.84 X_{3}+3.57 X_{1} X_{2} \\
& +3.00 X_{1} X_{3}-1.17 X_{2} X_{3}-3.18 X_{1}^{2}+1.19 X_{2}^{2}+2.92 X_{3}^{2}
\end{aligned}
$$

$$
\begin{aligned}
\text { Equivalent weight }(\mathrm{mg})= & 675.28+21.15 X_{1}+38.01 X_{2} \\
& +20.69 X_{3}+48.18 X_{1} X_{2} \\
& +59.68 X_{1} X_{3}-71.46 X_{1}^{2} \\
& +18.61 X_{2}^{2}+47.41 X_{3}^{2}
\end{aligned}
$$

Methoxyl content $(\%)=7.04+0.040 X_{1}+0.11 X_{2}+0.023 X_{3}-0.042 X_{1} X_{2}$

$$
+0.018 X_{1} X_{3}-0.016 X_{2} X_{3}-0.15 X_{1}^{2}+0.033 X_{2}^{2}-0.053 X_{3}^{2}
$$

The sign and magnitude of the coefficients in above Eqs. (1, 2 and 3 ) indicate the effect of the significant independent variables on the responses. From the above equations, it was observed that the positive coefficient of solid-solvent ratio $\left(X_{1}\right)$, ultrasound power intensity $\left(X_{2}\right)$ and sonication time $\left(X_{3}\right)$ signified the increase in the pectin yield, equivalent weight and methoxyl content, respectively, with increase in level of these parameters. However, the larger coefficient of ultrasound power intensity $\left(X_{2}\right)$ showed the higher effect on all the responses in comparison with other independent variables. In Eq. 1, the positive coefficient of combined effect of solid-solvent ratio and ultrasound power intensity $\left(X_{1} X_{2}\right)$ and solid-solvent ratio and sonication time $\left(X_{1} X_{3}\right)$ on the pectin yield suggests that pectin yield increases when high level of solid-solvent ratio was used with high level of ultrasound power intensity and when high level of solid-solvent ratio was used with high level of sonication time, respectively. However, the negative coefficient of combined effect of ultrasound power intensity and sonication time $\left(X_{2} X_{3}\right)$ on the pectin yield suggests that it decreases when high ultrasound power intensity was used with increased sonication time. At quadratic level, the negative coefficient of solid-solvent ratio $\left(X_{1}^{2}\right)$ showed that pectin yield decrease with increase in level of this parameter. However, at quadratic level, the positive coefficient of ultrasound power intensity $\left(X_{2}^{2}\right)$ and sonication time $\left(X_{3}^{2}\right)$ signified that when its level increased the pectin yield also increased. Similarly, in Eq. 2, at interactive level, the positive coefficient of $X_{1} X_{2}$ and $X_{1} X_{3}$ suggests that the equivalent weight increases when solid-solvent ratio was used with high level of ultrasound power intensity and when high level of solidsolvent ratio was used with high level of sonication time, respectively. At quadratic level, the negative coefficient of solid-solvent ratio $\left(X_{1}^{2}\right)$ showed that equivalent weight decrease with increase in level of this parameter. However, at quadratic level, the positive coefficient of ultrasound power intensity $\left(X_{2}^{2}\right)$ and sonication time $\left(X_{3}^{2}\right)$ signified 


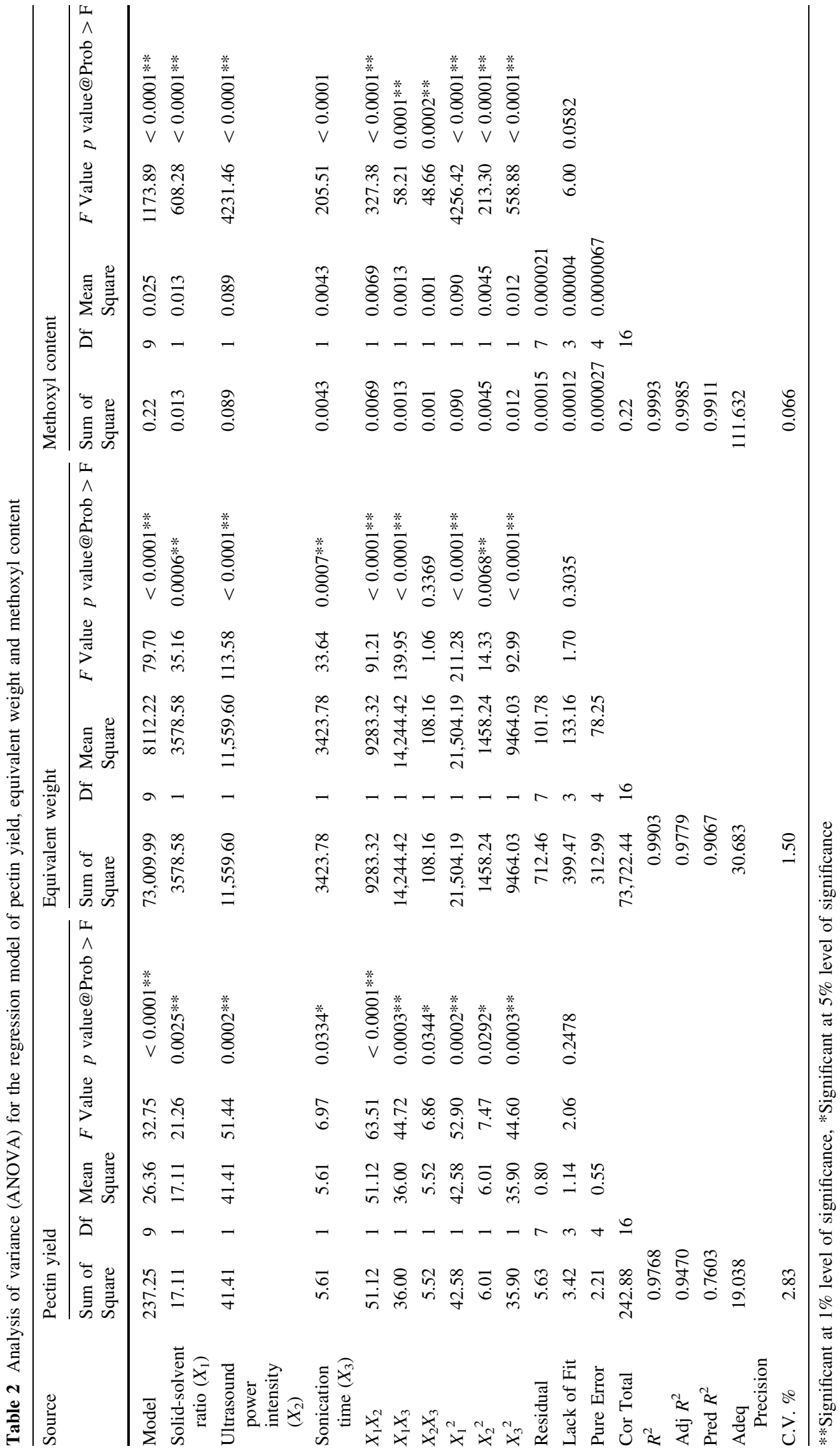


that when its level increased, the equivalent weight also increased. Additionally, in Eq. 3, the positive coefficient of $X_{1} X_{3}$ suggests that the methoxyl content increases when high level of solid-solvent ratio was used with high level of sonication time. However, the negative coefficient of $X_{1} X_{2}$ and $X_{2} X_{3}$ suggests that the methoxyl content decreases when high level of solid-solvent ratio was used with increased ultrasound power intensity and when high ultrasound power intensity was used with increased sonication time, respectively. At quadratic level, the negative coefficient of $X_{1}{ }^{2}$ and $X_{3}{ }^{2}$ showed that methoxyl content decrease with increase in level of solid-solvent ratio and sonication time, respectively. However, at quadratic level, the positive coefficient of $X_{2}^{2}$ signified that when the level of ultrasound power intensity increased, the methoxyl content also increased.

\section{Analysis of 3 D Graphs of pectin Yield, Equivalent Weight and Methoxyl Content}

For better understanding, the effect of processing parameters (solid-solvent ratio, ultrasound power intensity and sonication time) on the pectin yield, equivalent weight and methoxyl content was evaluated and illustrated by threedimensional plots (3D) in Fig. 3. Ultrasound power intensity was one of the effective factors in ultrasound-assisted extraction technique since the maximum pectin yield was observed at higher level of ultrasound power intensity with increase in solid-solvent ratio (Fig. 3a). This increase in pectin yield might be because of the disruption of cell wall and release of cellular material at sufficient higher ultrasound power intensity by De Oliveira et al. [4]. Fig. 3b showed that the pectin yield increased with increase in solid-solvent ratio and sonication time. This increase might be because of the increasing time that offers more reaction opportunity with the solvent. Longer contact time between the extractor and the plant materials provide greater mass transfer from the solid particles into the solution. In addition, higher solid-liquid ratio favors the yield by increasing the contact surface of the plant material with the solvent and enhances the swelling of the material, leading to cell disruption and thereby facilitates the solubilization of pectin [18].

Equivalent weight is an important response to check out the quality characteristics of the sweet lime peel pectin. Equivalent weight of pectin is the total content of free galacturonic acid (not esterified) in the molecular chains of pectin [21]. The increased or decreased equivalent weight might be dependent upon the amount of free acid [17]. The higher equivalent weight might be due to higher ultrasound power intensity which facilitates the release of higher amount of pectin, which will increases the equivalent weight of pectin (Fig. 3d). However, the lower equivalent weight could be due to higher partial degradation of pectin during extraction [11]. Fig. 3e showed that the equivalent weight increased rapidly when solid-solvent ratio increased from $1: 18$ to $1: 24 \mathrm{~g} / \mathrm{ml}$ with the increase in sonication time from 15 to $35 \mathrm{~min}$, while it decreased further at the highest value of solid-solvent ratio along with the lower value of sonication time. In this study, the equivalent weight of pectin ranged almost in the range of International Pectin Producers Association standard of 600-800 mg [9].

The methoxyl content in pectin has important role in determining the functional properties of pectin and the structure and texture of the pectin gel. Methoxyl content is the number of moles of methyl alcohol in $100 \mathrm{~mol}$ galacturonic acids. Methoxyl content is an important factor in controlling the setting time of pectin and the ability of the pectin to form gels [3]. Methoxyl content of the extracted pectin in the present study ranged between 6.7 and $7.1 \%$, which almost meet the standard of $2.5-7.2 \%$ [9]. It was observed that the methoxyl content of the extracted pectin in the present study was higher than the methoxyl content reported as $4.11 \%$ for lime, $3.9 \%$ for orange and $4.2 \%$ for grapefruit by Mohamed [15]. Figure $3 \mathrm{f}-\mathrm{h}$ ) shows the behavior of solid-solvent ratio, ultrasound power intensity and sonication time on the methoxyl content value. Figure $3 \mathrm{f}$ represents that the higher methoxyl content was found at the higher levels of ultrasound power intensity $\left(80 \mathrm{~W} / \mathrm{cm}^{2}\right)$ and solid-solvent ratio of $1: 24 \mathrm{~g} / \mathrm{ml}$. Also, pectin with higher methoxyl content values could be obtained around the central values of solid-solvent ratio and sonication time (Fig. 3. However, the further increase in both the variables reduced the methoxyl content due likely to chain cleavage into smaller fragments of pectin molecule [1]. Fig. 3h displayed that the methoxyl content increased with the increase in ultrasound power intensity and sonication time. This increase might be due to the higher effect of ultrasound power intensity. Ultrasound power intensity plays an important role in breaking up the vegetal tissue and thus enhanced the extraction yield which in turn increase the quality attributes [25].

\section{Conclusion}

As per the current scenario of production of sweet lime peel at small juice extraction units and household, most of the peel is discarded as waste without the knowledge of the extraction of pectin from the waste. It is apparent from the present study that pectin was extracted from the sweet lime peel using ultrasound-assisted extraction technique which is proved to be an efficient extraction technique because of its reduced extraction time, lower use of solvent, less consumption of power and improved yield of extraction. The best optimum conditions were obtained as solid- 


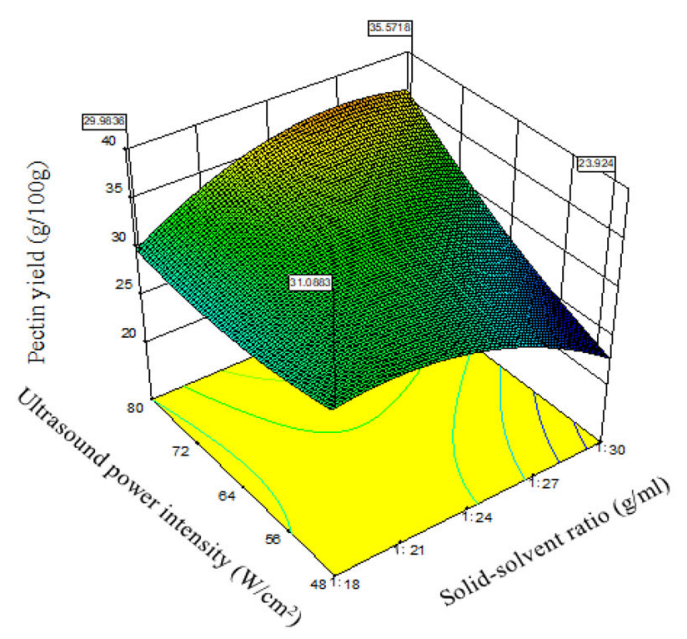

(A)

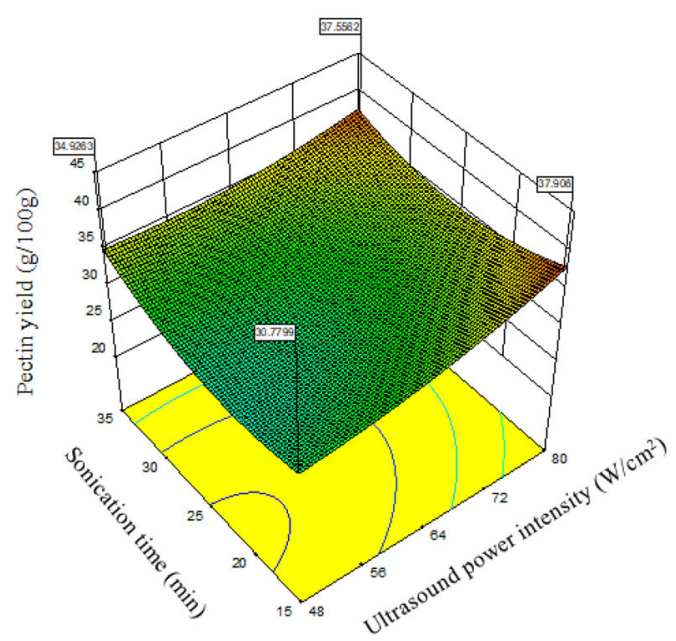

(C)

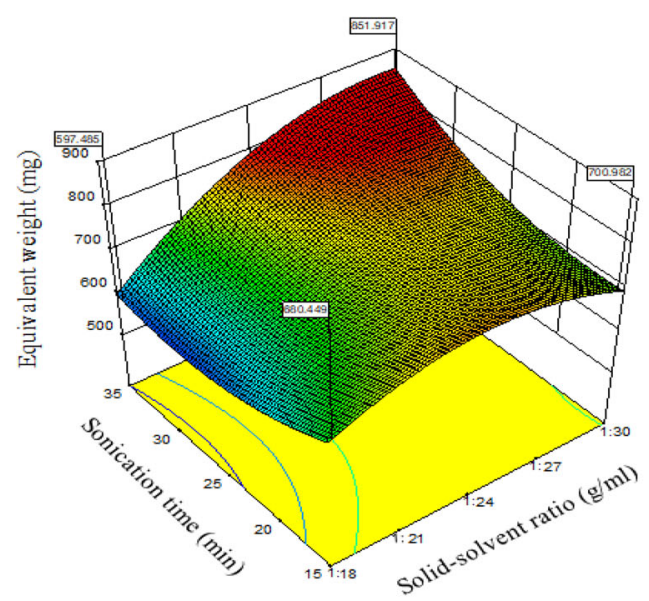

(E)

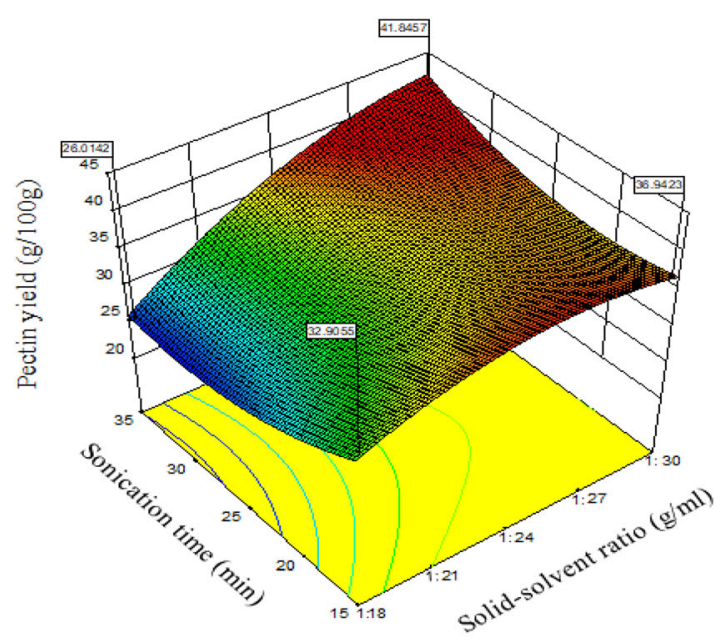

(B)

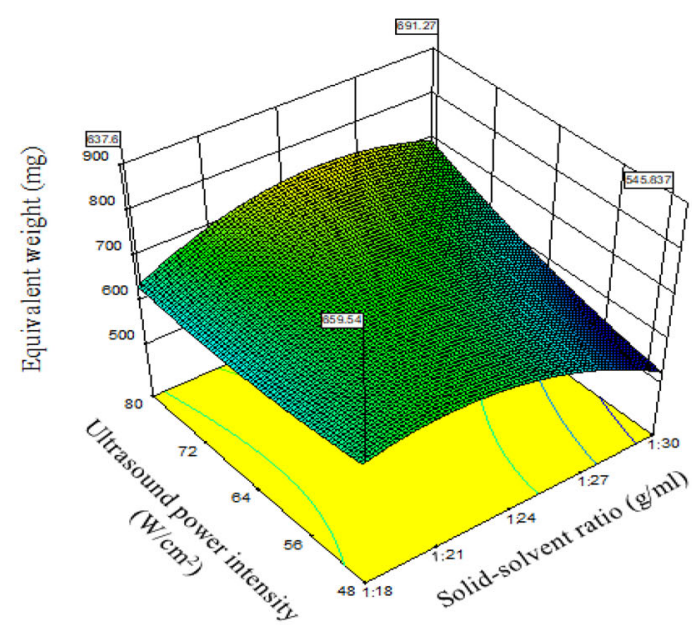

(D)

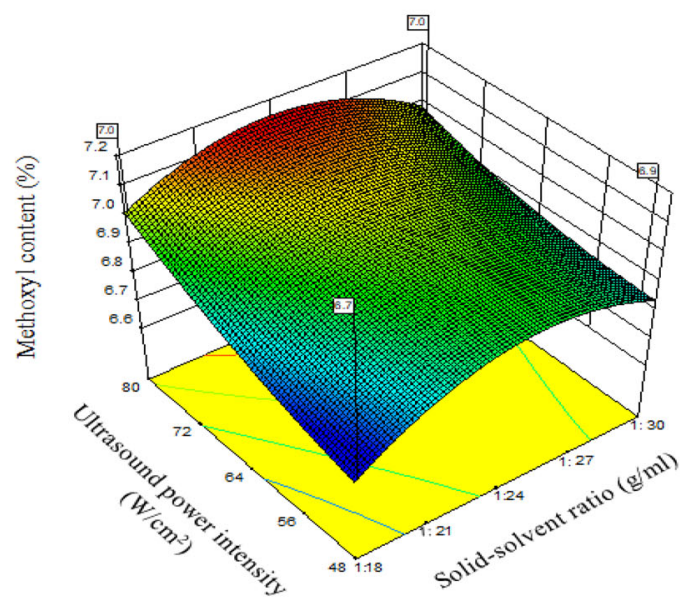

(F)

Fig. 3 3D plots showing the effect of processing variables on pectin yield, equivalent weight and methoxyl content 


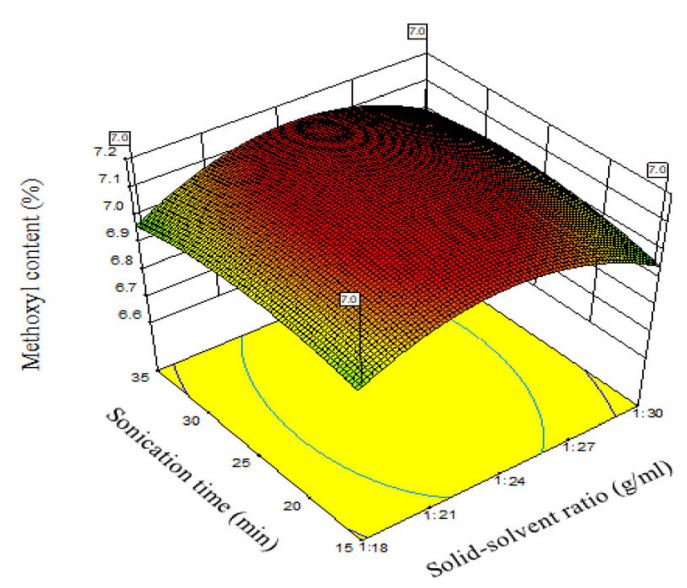

(G)

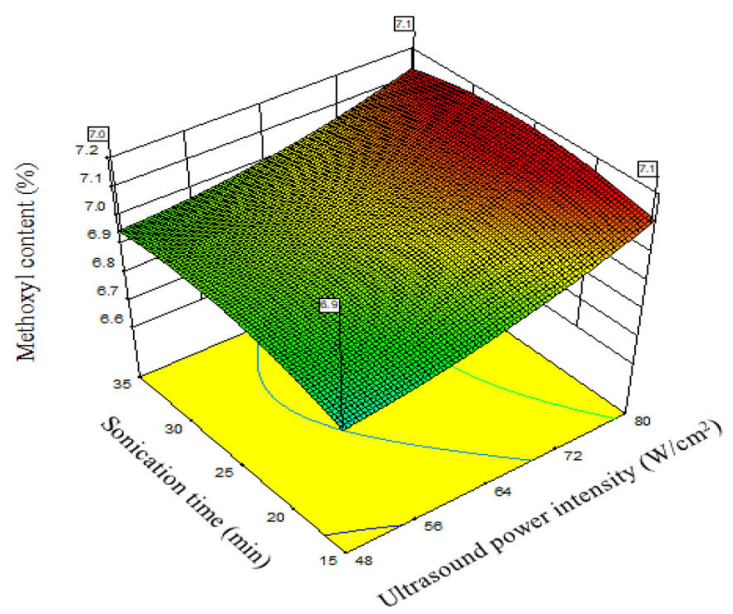

(H)

Fig. 3 continued

solvent ratio of $1: 24.3 \mathrm{~g} / \mathrm{ml}$, ultrasound power intensity of $80 \mathrm{~W} / \mathrm{cm}^{2}$ and sonication time of $18.4 \mathrm{~min}$ to produce maximum pectin. Under these conditions, the maximum pectin yield, equivalent weight and methoxyl content were $36.4 \mathrm{~g} / 100 \mathrm{~g}, 740.3 \mathrm{mg}$ and $7.1 \%$, respectively.

Acknowledgements We, the authors would like to thank Dean College of Technology and Head, Department of PHPFE, GBPUA\&T, Pantnagar, India for providing research facilities, financial support and technical assistance for extraction of pectin from sweet lime peel. Also thank to Coordinator, Technical Education Quality Improvement Programme (TEQIP-III) College of Technology, Pantnagar for sanctioning the grant for conducting the research work.

Open Access This article is licensed under a Creative Commons Attribution 4.0 International License, which permits use, sharing, adaptation, distribution and reproduction in any medium or format, as long as you give appropriate credit to the original author(s) and the source, provide a link to the Creative Commons licence, and indicate if changes were made. The images or other third party material in this article are included in the article's Creative Commons licence, unless indicated otherwise in a credit line to the material. If material is not included in the article's Creative Commons licence and your intended use is not permitted by statutory regulation or exceeds the permitted use, you will need to obtain permission directly from the copyright holder. To view a copy of this licence, visit http://creativecommons.org/licenses/by/4.0/.

\section{References}

1. H. Bagherian, F.Z. Ashtiani, A. Fouladitajar, M. Mohtashamy, Comparisons between conventional, microwave- and ultrasoundassisted methods for extraction of pectin from grapefruit. Chem. Eng. Process. 50(11-12), 1237-1243 (2011)

2. F. Chemat, N. Rombaut, A.G. Sicaire, A. Meullemiestre, A.S. Fabiano-Tixier, M. Abert-Vian, Ultrasound assisted extraction of food and natural products. Mechanisms, techniques, combinations, protocols and applications: a review. Ultrason. Sonochem. 34, 540-560 (2017)

3. D. Constenla, J.E. Lozano, Kinetic model of pectin demethylation. Latin Am. Appl. Res. 33(2), 91-95 (2003)

4. C.F. De Oliveira, D. Giordani, R. Lutckemier, P.D. Gurak, F. Cladera-Olivera, L.D.F. Marczak, Extraction of pectin from passion fruit peel assisted by ultrasound. LWT-Food Sci. Technol. 71, 110-115 (2016)

5. G. Garcia-Garcia, J. Stone, S. Rahimifard, Opportunities for waste valorisation in the food industry-A case study with four UK food manufacturers. Journal of Cleaner Production 211 , 1339-1356 (2019)

6. A.N. Grassino, M. Brnčić, D. Vikić-Topić, S. Roca, M. Dent, S.R. Brnčić, Ultrasound assisted extraction and characterization of pectin from tomato waste. Food Chem. 198, 93-100 (2016)

7. S.B. Hawthorne, C.B. Grabanski, E. Martin, D.J. Miller, Comparisons of Soxhlet extraction, pressurized liquid extraction, supercritical fluid extraction and subcritical water extraction for environmental solids: recovery, selectivity and effects on sample matrix. J. Chromatogr. 892(1-2), 421-433 (2000)

8. S.S. Hosseini, F. Khodaiyan, M. Kazemi, Z. Najari, Optimization and characterization of pectin extracted from sour orange peel by ultrasound assisted method. Int. J. Biol. Macromol. 125, 621-629 (2019)

9. International Pectin Producers Association (IPPA). Pectin commercial production and pectin in organic food products (2014)

10. G.M. Kamal, F. Anwar, A.I. Hussain, N. Sarri, M.Y. Ashraf, Yield and chemical composition of Citrus essential oils as affected by drying pretreatment of peels. Int. Food Res. J. 18(4), 1275 (2011)

11. S.G. Kulkarni, P. Vijayanand, Effect of extraction conditions on the quality characteristics of pectin from passion fruit peel (Passifloraedulisf.flavicarpa L.). LWT-Food Sci. Technol. 43(7), 1026-1031 (2010)

12. S.Q. Liew, N.L. Chin, Y.A. Yusof, Extraction and characterization of pectin from passion fruit peels. Agric. Agric. Sci. Procedia 2, 231-236 (2014)

13. D. Mamma, P. Christakopoulos, Biotransformation of citrus byproducts into value added products. Waste and Biomass Valoriz. 5(4), 529-549 (2014) 
14. N. Mirabella, V. Castellani, S. Sala, Current options for the valorization of food manufacturing waste: a review. J. Clean. Product. 65, 28-41 (2014)

15. H. Mohamed, Extraction and characterization of pectin from grapefruit peels. MOJ Food Process. Technol. 2(1), 00029 (2016)

16. I.G. Moorthy, J.P. Maran, S. Muneeswari, S. Naganyashree, C.S. Shivamathi, Response surface optimization of ultrasound assisted extraction of pectin from pomegranate peel. Int. J. Biol. Macromol. 72, 1323-1328 (2015)

17. R. Nazaruddin, Effect of ammonium oxalate and acetic acid at several extraction time and $\mathrm{pH}$ on some physicochemical properties of pectin from cocoa husks (Theobroma cacao). Afr. J. Food Sci. 5(15), 790-798 (2011)

18. B. Pasandide, F. Khodaiyan, Z.E. Mousavi, S.S. Hosseini, Optimization of aqueous pectin extraction from Citrus medica peel. Carbohyd. Polym. 178, 27-33 (2017)

19. S. Rafiq, R. Kaul, S.A. Sofi, N. Bashir, F. Nazir, G.A. Nayik, Citrus peel as a source of functional ingredient: a review. J. Saudi Soc. Agric. Sci. 17(4), 351-358 (2018)

20. Z. Rahmani, F. Khodaiyan, M. Kazemi, A. Sharifan, Optimization of microwave-assisted extraction and structural characterization of pectin from sweet lemon peel. Int. J. Biol. Macromol. 147, 1107-1115 (2020)
21. Ranganna S. Sensory evaluation, Handbook of analysis and quality control for fruit and vegetables products.Tata McGraw Hill Education Private Ltd, New York, USA (1951).

22. P. Rodsamran, R. Sothornvit, Lime peel pectin integrated with coconut water and lime peel extract as a new bioactive film sachet to retard soybean oil oxidation. Food Hydrocoll. 97, 105173 (2019)

23. R. Sindhu, E. Gnansounou, S. Rebello, P. Binod, S. Varjani, I.S. Thakur, R.B. Nair, A. Pandey, Conversion of food and kitchen waste to value-added products. J. Environ. Manage. 241, 619-630 (2019)

24. B.K. Tiwari, Ultrasound: a clean, green extraction technology. TrAC, Trends Anal. Chem. 71, 100-109 (2015)

25. M. Toma, M. Vinatoru, L. Paniwnyk, T.J. Mason, Investigation of the effects of ultrasound on vegetal tissues during solvent extraction. Ultrason. Sonochem. 8(2), 137-142 (2001)

26. M. Wang, B. Huang, C. Fan, K. Zhao, H. Hu, X. Xu, S. Pan, F. Liu, Characterization and functional properties of mango peel pectin extracted by ultrasound assisted citric acid. Int. J. Biol. Macromol. 91, 794-803 (2016)

Publisher's Note Springer Nature remains neutral with regard to jurisdictional claims in published maps and institutional affiliations. 